\title{
Contribuição da interação social no ambiente virtual de ensino e aprendizagem para 0 desempenho de alunos de um curso a distância de formação continuada de professores
}

\author{
Jany Baena Fernandez* \\ Dulce Márcia Cruz ${ }^{* *}$
}

\begin{abstract}
Resumo
Muito vem sendo feito visando responder à necessidade de formação continuada de professores para potencializar as práticas pedagógicas, por meio da mediação pedagógica com o uso dos recursos da Web 2.0, mas ainda pouco se sabe do peso que a interação que ocorre nos ambientes virtuais utilizados nesses cursos tem na avaliação dos estudantes. $\mathrm{O}$ objetivo principal da pesquisa cujos resultados serão aqui trazidos foi investigar o quanto a quantidade de interação social no fórum virtual de um curso a distância para docentes que atuam na gestão de tecnologias nas escolas contribuiu para seu desempenho e sua avaliação. A pesquisa investigou o caso do Curso "Ambiente Virtual de Aprendizagem no contexto da Aprendizagem e Avaliação", oferecido entre 2011 e 2013, pela Secretaria Municipal de Educação para Coordenadores de Suporte Pedagógico de Tecnologia da Rede Municipal de Educação de Campo Grande, Mato Grosso do Sul, e teve a participação de dois docentes mediadores e de vinte e nove professores cursistas. Verificou-se que a interação permeia positivamente todo o processo de aprendizagem, contribuindo para o desempenho dos cursistas e a produção coletiva e colaborativa. No entanto, são inconclusivas as ligações entre quantidade de interação e avaliação positiva, já que em uma turma estudada essa relação foi direta, mas em outra não, o que sugere a necessidade de mais estudos sobre essa questão.

Palavras-chave: Interação. Ambiente virtual. Avaliação.
\end{abstract}

\section{Introdução}

Os Coordenadores de Suporte Pedagógico de Tecnologia (CSPTEC) da Rede Municipal de Educação (REME) de Campo Grande - MS - atuam na gestão do uso das Tecnologias da Informação e Comunicação - TIC - e são destinados a ampliar

Professora formadora da Secretaria Municipal de Educação do município de Campo Grande (MS) e Mestranda em Estudos de Linguagens (UFMS).

** Universidade Federal de Santa Catarina (UFSC). 
o êxito na aprendizagem dos alunos, bem como proporcionar à comunidade escolar a fluência tecnológica necessária à sociedade contemporânea. Para eles, foi desenvolvido, entre 2011 e 2013, o Curso Ambiente Virtual de Aprendizagem - AVA no contexto da Aprendizagem e Avaliação pela Secretaria Municipal de Educação (SEMED), por meio da Divisão de Tecnologia Educacional (DITEC), em Campo Grande - MS. Nesse curso, os profissionais de educação desempenham o papel de docente e mediador ao mesmo tempo, não se separando a função de tutor da do professor como em muitos dos cursos a distância. O curso foi estruturado em $160 \mathrm{~h}$, no período de oito meses, por meio do Moodle, na modalidade a distância. Os encontros presenciais aconteciam de quinze em quinze dias, no laboratório da DITEC/SEMED, com duração de quatro horas, sendo constituídos por nove módulos, com atividades teóricas e práticas.

Essa formação teve o propósito de potencializar as práticas pedagógicas, por meio da mediação pedagógica com o uso dos recursos da Web 2.0, de maneira significativa, com a finalidade de promover a autonomia e a aprendizagem de professores e alunos no contexto escolar.

Por ser um curso com momentos presenciais e a distância, os professores mediadores acompanhavam diária e sistematicamente os trabalhos dos cursistas, em que se propunham produções textuais coletivas e colaborativas aos participantes. Nesse sentido, pressupunha uma aprendizagem mais significativa, que envolvesse atividades de interação entre os partícipes. Esse aspecto despertou o interesse em realizar um estudo sobre a contribuição da troca de informações entre os estudantes nos cursos de formação continuada $\mathrm{EaD}$ de professores, dada a importância da interação na educação a distância, como destaca Giordan (2006):

Em situações de educação a distância, o diálogo interativo ocupa papel central na aprendizagem, pois contribui para a (re)elaboração de significados gerados a partir das múltiplas vozes referidas em cada enunciação. A aprendizagem dialógica é um processo que promove o reposicionamento do sujeito no horizonte conceitual do outro e a apropriação de gêneros de discurso e atitudes científicas. (Apud TOSTES, 2011, p. 181).

Além da relevância dialógica, a interação tem uma importância histórica nos estudos voltados para desenvolvimento da aprendizagem, pois, segundo Vygotsky,

o desenvolvimento intelectual ocorre em função das interações sociais e condições de vida. Ele enfatizava o processo histórico- 
social e o papel da linguagem no desenvolvimento do indivíduo. Sua questão central é a aquisição de conhecimentos pela interação do sujeito com o meio. Para o teórico, o sujeito é interativo, pois adquire conhecimentos a partir de relações intra e interpessoais e de troca com o meio. Segundo ele, o grupo cultural fornece ao indivíduo um ambiente estruturado onde os elementos são carregados de significado cultural. Isto ocorre graças à inclusão do indivíduo no meio cultural, permitindo a interação com outros já ricos da cultura que dispõem. Isto possibilita ao indivíduo realizar operações cada vez mais complexas, perante um aspecto cognitivo, no qual o ser humano se desenvolve a partir do aprendizado, que envolve a interferência direta ou indireta de outros seres humanos. (Apud ARAÚJO, 2011, p. 30).

Sendo assim, foi realizada uma pesquisa, defendida em forma de monografia de conclusão para o Curso de Especialização em Gestão e Docência em EaD Rede e-Tec Brasil (FERNANDEZ, 2013), com o objetivo de investigar como se dá a interação num Ambiente Virtual de Ensino e Aprendizagem (AVEA) e se ela contribui para o desempenho dos alunos, bem como para a produção coletiva e colaborativa, num fórum de um AVEA, em um curso de formação continuada de professores.

Utiliza-se 'desempenho', neste trabalho, para se fazer referência ao resultado da avaliação obtida pelos professores cursistas, ou seja, notas que são consideradas registros formais e objetivos da atuação de estudantes. No entanto, é importante frisar que a avaliação é mais ampla e envolve aspectos quantitativos e qualitativos, conforme afirma Hoffmann (2005, p. 50):

A quantidade é apenas umas das dimensões de um objeto ou fenômeno. Poucas qualidades de um objeto podem ser expressas por medidas quantitativas, tais como peso, volume, tamanho, exigindo, na maioria das vezes, que se façam descrições de qualidade para esclarecer melhor o que os dados quantitativos mostraram, ou seja, para explicar melhor o objeto medido.

Porém, o curso investigado atribui notas na maioria das atividades, inclusive na participação dos fóruns, sendo exigidas, no mínimo, três participações por cursista. Dessa maneira, são relacionadas às contribuições nos fóruns dos professores cursistas, a fim de fazer uma análise descritiva dessas variáveis (notas e contribuições nos fóruns). As notas são públicas aos alunos, que podem visualizálas no Moodle, o ambiente virtual utilizado no curso. Os mediadores, ao atribuí-las, 
levam em consideração os critérios estabelecidos pela equipe de professores para aplicação da nota, que são: 1) atendimento à proposta, 2) coerência e coesão do texto, 3) norma culta e 4) embasamento teórico relacionado às leituras obrigatórias do módulo.

Os professores da educação básica lidam diariamente com crianças e jovens, inseridos em uma sociedade que evolui rapidamente, em virtude dos avanços tecnológicos. Nesse contexto, ressalta-se a importância desta pesquisa pela necessidade de se conhecer melhor a formação continuada oferecida aos docentes para acompanhar as mudanças da sociedade contemporânea, a fim de atualizar e aprimorar a prática pedagógica tanto da oferta como dos cursistas.

Sob essa ótica, este estudo pretende contribuir para a democratização de cursos de formação continuada, com a expansão de acesso a várias áreas do conhecimento e divulgação dos recursos tecnológicos para a formação de educadores em âmbito educacional. Também, entende-se que os cursos a distância ou semipresenciais têm relevância econômica e social, uma vez que essas modalidades ampliam espaços e tempos para a realização de estudos, pois os professores não precisam se deslocar e seu horário de estudo é flexível.

Além disso, este estudo também pode contribuir para o desenvolvimento e aprimoramento de cursos na área educacional, pois trata sobre um aspecto, pertinente ao AVEA, que é o de promover a interação, visando destacar a sua importância como fator motivador para o ensino e a aprendizagem, bem como para uma discussão sobre formação continuada de professores pela identificação de abertura para futuras pesquisas.

No sentido mais restrito, a intencionalidade de se investigar o curso no contexto da aprendizagem e avaliação deveu-se à sua especificidade, ou seja, a elaboração realizada pela equipe da DITEC/SEMED/MS de forma autônoma, sem a exigência de um programa emanado de uma estrutura hierárquica. Ou seja, o projeto do curso foi produzido a partir de uma necessidade local, visando aos objetivos estabelecidos pela gestão da SEMED, que prioriza o estudo teórico, aliado à prática e a uma pesquisa docente.

\section{Formação continuada de professores}

A formação continuada perpassa todos os campos educacionais e, nesse sentido, Nóvoa afirma que 
importa valorizar paradigmas de formação que promovam a preparação de professores reflexivos, que assumam a responsabilidade do seu próprio desenvolvimento profissional e que participem como protagonistas na implementação das políticas educativas (1992, p. 27).

Deve-se enfatizar a reflexão, conforme mencionado pelo autor, para que haja mudanças, transformações na prática pedagógica. Para isso é necessário ter claros os objetivos na elaboração das formações, a fim de que se alcance a efetiva aprendizagem. Nesse sentido, entende-se, de acordo com Nóvoa (1992), que os cursos devem priorizar a formação de professores pesquisadores que reflitam sobre a sua potencialidade e o que ela pode favorecer para a interferência na realidade escolar. Em tal perspectiva, ressalta-se a realidade escolar de cada professor, pois, em seu locus profissional, enfrenta dificuldades diárias, inerentes à diversidade dos estudantes que atende e de todo o contexto que envolve o seu fazer.

Entretanto, a formação continuada não deve visar somente à atuação individual, mas também à socialização dos saberes para a integração dos partícipes no grupo e do grupo, pois quando a formação é socializada e aceita na comunidade escolar, todos os profissionais envolvidos tornam-se corresponsáveis pelo sucesso escolar. Tratando a formação continuada a distância, Kenski aponta que ela deve ser

abrangente e orientada que envolva o conhecimento do processo pedagógico, a seleção e adequação da proposta de curso ou disciplina às especificidades dos meios tecnológicos envolvidos, a gestão do processo educacional em rede, a produção de materiais comunicativos, a condução dos processos e estratégias para acolhimento e permanência dos alunos em estado de aprendizagem permanente, entre tantas outras necessidades que são específicas dos múltiplos tipos de oferta de modalidades de cursos a distância (2013, p. 114).

Além dos aspectos mencionados pela autora, faz-se necessária a abertura na escola para que os professores coloquem em prática o conhecimento adquirido e/ou reformulado. Essas atualizações são essenciais, devido às mudanças sofridas pela sociedade e a interferência direta na postura dos alunos que aprendem de forma diferenciada e exigem novas formas de ensino, o que se reflete na educação escolar. 
Diante disso, o conhecimento continuado assume um papel de destaque e vislumbra um profissional reflexivo, autônomo, atuante e, principalmente, integrado ao seu contexto social, pois essa formação não deve atingir somente os professores, mas toda a instituição. Nesse sentido, Azanha (1990, p. 52) enfatiza que

a questão da qualidade do ensino é, pois, uma questão institucional. São as escolas que precisam ser melhoradas. Sem este esforço institucional, o aperfeiçoamento isolado docente não garante que essa eventual melhoria do professor encontre na prática as condições propícias para uma melhoria do ensino.

Daí a necessidade de se pensar em expansão das políticas de formação continuada em atendimento a todos os envolvidos no processo educacional, além de investimento em infraestrutura física nas unidades escolares, a fim de minimizar as necessidades das instituições de ensino. Com isso, a utilização de recursos como o ambiente virtual permite uma flexibilização do ensino presencial, permitindo uma ampliação de abrangência e de possibilidades de oferta, contribuindo para a realização da formação continuada em serviço, sem o afastamento total dos professores de suas rotinas profissionais.

\section{Ambiente virtual - conceitos de AVA e AVEA}

O ambiente virtual como recurso para o ensino e aprendizagem está muito presente na educação a distância $(\mathrm{EaD})$, pois sua estrutura atende às necessidades de comunicação entre os participantes, ao acesso aos materiais do curso, ao desenvolvimento de atividades, à visualização dos feedbacks e notas de professores, entre outros. Porém ele não se limita somente à $\mathrm{EaD}$, podendo ser também utilizado como complemento e apoio nas modalidades presenciais e semipresenciais, de acordo com a regulamentação estabelecida pela Portaria $n^{0}$ 4.059, de 10 de dezembro de 2004 (BRASIL, 2004).

Na literatura, são comuns dois termos (Ambiente Virtual de Aprendizagem, AVA, e Ambiente Virtual de Ensino e Aprendizagem, AVEA), para designar os ambientes virtuais utilizados para fins educativos. A fim de se entender a distinção entre essas duas acepções, buscou-se em Roncarelli et al. (2007, p. 3-4) um detalhamento das características que os diferenciam: 
Um AVA é conhecido, de modo geral, na literatura internacional como LMS (Learning Management System - Sistema de Gestão da Aprendizagem) ou como VLE (Virtual Learning Environment - Ambiente Virtual de Aprendizagem). Entende-se nesse estudo AVEA como um sistema que disponibiliza diversas ferramentas de comunicação e interação. Tem o propósito de promover aprendizagem não desvinculada de um processo de ensino que é sistemático, organizado, intencional e tem caráter formal. Um AVEA diferencia-se de um AVA porque contempla quatro pilares: sistematização, organização, intencionalidade pedagógica e caráter formal/institucional.

Dessa forma, compreende-se, para a presente pesquisa, que o AVEA é mais complexo e completo. Sua estrutura pode ser organizada de uma forma que atenda aos professores e estudantes, fazendo com que se estreite a relação entre ensino e aprendizagem. Com isso, a organização e a sistematização do ensino podem contribuir muito para a aprendizagem do estudante. Para tanto, é necessário que o professor selecione as ferramentas, os textos para estudo e pesquisa e seja autônomo na elaboração das atividades, criando espaços no AVEA a fim de que o ensino contribua efetivamente para a aprendizagem.

Porém, um determinado ambiente virtual pode ser AVA ou AVEA, dependendo da maneira como é organizado e da sua intencionalidade, pois as ferramentas de interação e comunicação dos ambientes proporcionam a elaboração de espaços que não se restringem somente a repositórios de textos. Diante disso, enfatiza-se que o AVEA possua regulamentos, formas, características institucionais voltadas especificamente para o pedagógico. Para isso, a instituição que o utiliza pode explorar várias ferramentas de comunicação e interação, a fim de levar o estudante a relacionar, problematizar, criar, produzir individualmente e, principalmente, em regime de colaboração, sempre com a presença e mediação do professor.

O AVEA utilizado na formação continuada que é alvo de nossa pesquisa é o Moodle, "uma plataforma de aprendizagem projetada para fornecer aos educadores, administradores e alunos um único sistema robusto, seguro e integrado para criar ambientes de aprendizagem personalizados" (MOODLE, 2013). Segundo a Wikipédia (2013), "em linguagem coloquial, em língua inglesa o verbo 'to moodle' descreve o processo de navegar despretensiosamente por algo, enquanto fazem-se outras coisas ao mesmo tempo." Para seu criador, Dougiamas (2001), o Moodle é um aplicativo web gratuito que os educadores podem utilizar na criação de sites de aprendizado eficazes. 
O Moodle possui uma flexibilidade quanto ao uso dos recursos, pois os conteúdos didáticos disponibilizados no ambiente possibilitam aos professores que os apresentem de forma estruturada ou pouco estruturada, de modo hipermidiático, com vistas a combinar recursos audiovisuais e interativos para expor conceitos complexos.

Assim, pode-se perceber que, nesse AVEA, existe a possibilidade de produzir e disponibilizar conteúdos, por meio de diferentes linguagens, usando as distintas mídias, para propiciar o desenvolvimento cognitivo dos estudantes. Dessa forma, o Moodle viabiliza a visualização das informações em múltiplas perspectivas, não lineares, contribuindo para potencializar um espaço de interação para as situações de ensinar e aprender.

\section{Interação e aprendizagem}

A relação entre interação e aprendizagem vem sendo abordada pelos estudiosos que contribuíram e contribuem para a concepção de educação implantada na sociedade contemporânea. Assim, observa-se, conforme estudo realizado por Rabello e Passos (2010, p. 7), um resumo das ideias de alguns dos teóricos mais representativos para essa discussão sobre a linguagem:

Piaget: o mecanismo interacionista - a linguagem faz parte de uma função mais ampla, que é a capacidade de representar a realidade através de significados que se distinguem de significantes.

Vygotsky: raízes genéticas do pensamento e da linguagem linguagem é considerada como instrumento mais complexo para viabilizar a comunicação, a vida em sociedade. Sem linguagem, o ser humano não é social, nem histórico, nem cultural.

Bruner: Psicologia cultural - defende a visão cultural do desenvolvimento da linguagem e coloca a interação social no centro de sua atenção sobre o processo de aquisição.

Cole: Sociocultural - para que a criança adquira mais do que rudimentos de linguagem, ela deve não apenas ouvir ou ver linguagem, mas também participar de atividades que a linguagem ajuda a criar e manter.

Como se pode ver pela síntese acima, para importantes autores que pesquisam a educação, a interação e a aprendizagem possuem uma relação estreita, concretizada por meio da linguagem. 
Ao interagir com um objeto, com um livro, com um professor, com um colega de estudo, acontecem trocas que podem ser mais ou menos intensas, proporcionando a aprendizagem, por meio de confirmações, contradições, acréscimos e principalmente pelas relações que a mente de quem está no papel de aprendiz estabelece. Assim confirma-se o que Vigotski (2010) menciona em seus estudos: para ocorrer o desenvolvimento intrapessoal, antes ocorre uma transformação interpessoal, ou seja, a relação com o social que determina o indivíduo. Também Vigotski (2010, p. 150) contribui na afirmação sobre desenvolvimento:

um complexo processo dialético, caracterizado pela periodicidade, irregularidade no desenvolvimento das diferentes funções, metamorfose ou transformação qualitativa de uma forma em outra, entrelaçamento de fatores externos e internos e processos adaptativos.

Sob essa ótica, a aprendizagem acontece a partir da interação social. Por isso desde as primeiras formas de ensinar já se estabelecia a interação de uma pessoa com outra pessoa, que era considerada mais sábia, com o objetivo de transformar as demais. Porém, com o passar do tempo, as informações foram disseminadas de forma mais rápida e por diversas mídias, mudando o papel do professor, que agora tem a função de mediar o processo de ensino/aprendizagem.

Como afirma Kenski, "interagir com o conhecimento e com as pessoas para aprender é fundamental. Para a transformação de um determinado grupo de informações em conhecimentos é preciso que estes sejam trabalhados, discutidos, comunicados" (2002, p. 258). Uma das vantagens das TIC (tecnologias de informação e comunicação) é que elas permitem a existência de uma aprendizagem contextualizada, em que se construam realidades virtuais trabalhando os temas abordados de forma que o estudante possa assimilar e adaptar esse conhecimento em novas circunstâncias. Por essa razão, o AVEA, que é constituído de recursos que propiciam a informação e a comunicação, não pode ficar dissociado da interação. As formas do ensinar e do aprender são intrinsecamente baseadas nas relações e ações efetuadas entre professores, cursistas/estudantes e ambiente virtual.

\section{Metodologia da pesquisa}

Para tentar entender as questões de investigação, foram levantados inicialmente nesta pesquisa os conceitos de Vigotski (2010), Kenski (2002, 2008 e 2013), 
relacionando os conhecimentos já existentes sobre interação, aprendizagem, cooperação e colaboração. A metodologia foi pautada no teórico Gil (2010); a análise de conteúdo segue os fundamentos de Bardin (1977) na interpretação dos dados das entrevistas dos mediadores.

A pesquisa teve como sujeitos professores dos anos iniciais e finais do ensino fundamental da Rede Municipal de Ensino (REME), formados nas diversas áreas, concursados para pelo menos 20 horas e que foram aprovados num processo seletivo simplificado. Sendo assim, dentro do universo de 100 professores cursistas e 10 mediadores pedagógicos do curso de formação continuada AVA, no contexto da Aprendizagem e Avaliação optou-se por realizar a pesquisa em duas turmas: B1 e B2. A justificativa é que a pesquisadora teve acesso direto às informações no Moodle, devido à liberação do ambiente virtual para o acesso a essas turmas, que, na realidade, formam a turma $\mathrm{B}$ do curso, dividida nos turnos matutino e vespertino. Também se teve preferência por essa turma devido à seguinte característica: os professores cursistas, na sua maioria, realizaram e postaram as atividades em tempo hábil e finalizaram o curso. Sendo assim, conseguiu-se selecionar as notas de quinze alunos da turma B1 e quatorze da turma B2.

Portanto, o processo de levantamento de dados desta pesquisa iniciou-se com o acesso ao projeto do curso de formação continuada, às legislações vigentes da SEMED que envolvem os sujeitos da pesquisa e suas atribuições. Em seguida, elaborou-se um questionário no Google Drive com o objetivo de investigar como se dá a interação social num AVEA, se ela contribui para o desempenho de alunos e se facilita a produção coletiva e colaborativa, no fórum, em um curso de formação continuada de professores. Esse questionário foi enviado por e-mail em um link, acessado a partir da internet e respondido de forma online, mostrando-se um recurso inovador para aplicação de questões para os alunos da $\mathrm{EaD}$.

Paralelamente acessou-se o Moodle do curso para se coletarem informações referentes às interações nos fóruns dos nove módulos do curso e às notas de sete módulos, pois os dois últimos foram os momentos de prática nas escolas - oficina com alunos e professores e finalização da produção multimodal no Google Site (Trabalho de Conclusão do Curso - TCC) para comparar as duas variáveis (notas e quantitativo de interação no fórum) e verificar se houve relação entre elas.

Por último, foi feita uma entrevista individual online com dois professores mediadores do curso, por meio do bate-papo do Gmail. A entrevista foi composta por questões semiestruturadas, a fim de levantar informações sobre planejamento, 
mediação, função dentro do curso; resultados obtidos, quanto tempo dedicaram ao trabalho; relevância e função do fórum, concepção de interação e características que ajudaram na aprendizagem. Essa ferramenta de bate-papo online, que gerou um texto escrito pelos entrevistados, também se mostrou um recurso inovador e útil para aplicação de questões a pesquisados envolvidos na EaD e na educação semipresencial.

\section{Resultados}

O instrumento usado para a realização das entrevistas foi o bate-papo do Gmail, uma sala virtual que dispõe de recursos escritos, visuais e auditivos. Optou-se pelo uso das mensagens, uma vez que todo o contexto que envolveu a pesquisa se baseou nas discussões de fóruns em ambientes virtuais, prevalecendo o registro escrito. Os diálogos foram salvos no e-mail da pesquisadora e partiu-se dos dados brutos originais para a realização da análise.

As entrevistas realizadas com os professores mediadores foram organizadas em categorias definidas após a coleta de dados, tendo como foco os objetivos da pesquisa. Os enunciados foram agrupados em cinco categorias, sendo que todas contemplaram a relação de um aspecto ou momento do curso com a interação social: interação no planejamento do professor mediador; interação entre professor mediador e cursista; interação no fórum; interação entre os professores cursistas; interação e produção coletiva e colaborativa do cursista.

Utilizou-se a Análise de Conteúdo de acordo com Bardin (1977), com objetivo de categorizar os dados, apropriando-se dos registros de frequência de aspectos relacionados à interação e à proximidade com enunciados e conceitos que envolvem o contexto do curso pesquisado. Para realizar a análise de conteúdo, primeiramente foi feita a leitura de todos os comentários dos cursistas, no questionário, e das respostas dos professores mediadores, nas entrevistas. Após a leitura foram identificadas as estruturas referentes à interação, que correspondiam ou se relacionavam com o objeto da pesquisa. Constatadas as frequências das estruturas ou vocábulos que remetiam à interação, utilizou-se o negrito para o destaque e comparação com a coluna das categorias elencadas.

A elaboração do quadro abaixo teve como base as respostas produzidas pelos professores mediadores durante a entrevista realizada por meio do bate-papo do Gmail. Os dados foram sistematizados e categorizados, considerando os aspectos relacionados à interação efetivada no curso AVA no contexto da aprendizagem e avaliação. 
QUADRO 1 - Categorias, referentes à concepção e à importância dada pelos professores mediadores a respeito do fórum e das interações com os cursistas

\begin{tabular}{|c|c|c|c|}
\hline N. & Categorias & Professor 1 & Professor 2 \\
\hline 1 & $\begin{array}{l}\text { Interação no } \\
\text { planejamento do } \\
\text { professor mediador }\end{array}$ & $\begin{array}{l}\text { "Fazíamos reunião } \\
\text { para discutirmos a } \\
\text { temática dos módulos e } \\
\text { escolhíamos os teóricos } \\
\text { e textos a serem } \\
\text { estudados." }\end{array}$ & $\begin{array}{l}\text { "Sempre levando ao grupo as } \\
\text { possibilidades de interação e } \\
\text { crescimento dos cursistas" }\end{array}$ \\
\hline 2 & $\begin{array}{l}\text { Interação entre } \\
\text { professor mediador e } \\
\text { cursista }\end{array}$ & $\begin{array}{l}\text { "A mediação acontecia } \\
\text { de maneira que os } \\
\text { cursistas enviavam } \\
\text { suas atividades e os } \\
\text { mediadores faziam } \\
\text { a devolutiva com } \\
\text { intervenções pontuando } \\
\text { os critérios que eles } \\
\text { deveriam melhorar em } \\
\text { suas produções para } \\
\text { que eles refletissem } \\
\text { sobre as leituras." }\end{array}$ & $\begin{array}{l}\text { "Por meio de mensagens, } \\
\text { feedbacks das tarefas, } \\
\text { sempre incentivando os } \\
\text { cursistas." }\end{array}$ \\
\hline 3 & Interação no Fórum & $\begin{array}{l}\text { "O fórum é uma } \\
\text { ferramenta do AVEA } \\
\text { que proporciona } \\
\text { interação, discussão, } \\
\text { debate aprendizagem. } \\
\text { è importante porque } \\
\text { devemos ser muito } \\
\text { objeto (sic) ao produzir } \\
\text { textos no fórum } \\
\text { devido proporcionar } \\
\text { esta grande interação } \\
\text { de ideia diferencias e } \\
\text { argumentativas." }\end{array}$ & $\begin{array}{l}\text { "Fórum é o momento } \\
\text { de expor ideias, discutir, } \\
\text { sugerir." }\end{array}$ \\
\hline
\end{tabular}




\begin{tabular}{|c|c|c|c|}
\hline 4 & $\begin{array}{l}\text { Interação entre os } \\
\text { professores cursistas }\end{array}$ & $\begin{array}{l}\text { "Os cursistas } \\
\text { interagiam muito } \\
\text { bem, devido os fóruns } \\
\text { deste curso terem uma } \\
\text { visão multimodal, } \\
\text { isso quer dizer, muitas } \\
\text { imagens, links, vídeos. } \\
\text { E com isso estimula } \\
\text { o cursista a contribuir } \\
\text { com suas participações } \\
\text { significativas conforme } \\
\text { o contexto da } \\
\text { temática." }\end{array}$ & $\begin{array}{l}\text { "A participação do fórum é } \\
\text { enriquecedora, pois ocorre } \\
\text { o posicionamento dos } \\
\text { cursistas, onde se elabora um } \\
\text { texto com o conhecimento } \\
\text { que tinha e agrega ao novo } \\
\text { que surgem das leituras, } \\
\text { formando um novo conceito } \\
\text { sobre um tema." }\end{array}$ \\
\hline 5 & $\begin{array}{l}\text { Interação e } \\
\text { produção coletiva } \\
\text { e colaborativa do } \\
\text { cursista }\end{array}$ & $\begin{array}{l}\text { "Acredito que interação } \\
\text { no decorrer do curso } \\
\text { contribuiu muito para } \\
\text { a produção textual } \\
\text { coletiva e colaborativa } \\
\text { com a utilização } \\
\text { dos recursos da } \\
\text { Web 2.0. O trabalho } \\
\text { coletivo enriqueceu o } \\
\text { potencial intelectual } \\
\text { dos cursistas para } \\
\text { que eles se tornassem } \\
\text { pesquisadores, autores } \\
\text { e autônomo." }\end{array}$ & $\begin{array}{l}\text { "Conhecer, discutir, avaliar } \\
\text { e rever a cada instante a } \\
\text { tarefa ou texto que é feita } \\
\text { coletivamente. Ter uma } \\
\text { visão geral e especifica para } \\
\text { poder contribuir com outros } \\
\text { cursistas." }\end{array}$ \\
\hline
\end{tabular}

FONTE: Dados da pesquisa retirada da Monografia do Curso de Especialização em Gestão e Docência em EaD pela Universidade Federal de Santa Catarina - Florianópolis.

(FERNANDEZ, 2013).

Constatou-se nos relatos dos professores que a interação social permeia todo o processo que envolve o curso, desde o seu preparo, pois a equipe se reunia para decidir e planejar o que seria desenvolvido no curso, perpassando a concepção de fórum, os feedbacks e, por fim, a produção textual coletiva.

A seguir, apresentam-se os gráficos que comparam a interação nos fóruns com as notas atribuídas aos cursistas pelos professores mediadores. Para a coleta e seleção dos dados foram utilizados mecanismos de busca e de emissão de relatório do próprio ambiente Moodle, com objetivo de verificar o número de participações de cada professor cursista e as notas atribuídas nas atividades dos nove módulos do curso. Além disso, utilizou-se a planilha de cálculo Excel para filtrar os cursistas que realmente participaram dos cursos. Por meio das fórmulas, conseguiram-se as médias das notas, maior nota e menor nota e número de 
interações nos fóruns. Por último, foram gerados os gráficos, selecionando os dados que interessam à pesquisa, ou seja, contemplando os objetivos.

Observa-se que nos Gráficos 1 e 2, abaixo, que obtiveram a maior e menor nota, a interação é proporcional à nota, ou seja, quanto mais interação, maior nota. Sob essa ótica, infere-se que a contribuição da interação social é vantajosa para os cursistas, pois, ao se compararem as duas variáveis, percebe-se uma relação direta entre elas, pois, quando há alteração em uma, a outra também sofre alteração, diretamente proporcional. Enfatiza-se que essa situação é visível no caso de se trabalhar com os dados dos extremos: maior e menor nota.

Os professores cursistas que interagiram bastante nos fóruns conseguiram um melhor desempenho durante o curso. Uma hipótese para isso seria que, possivelmente, ao dar a devolutiva e receber o retorno dos professores cursistas, o mediador acabou constatando o esforço, o interesse e o seu crescimento intelectual durante o processo, retribuindo com uma avaliação condizente com o seu desenvolvimento como estudante.

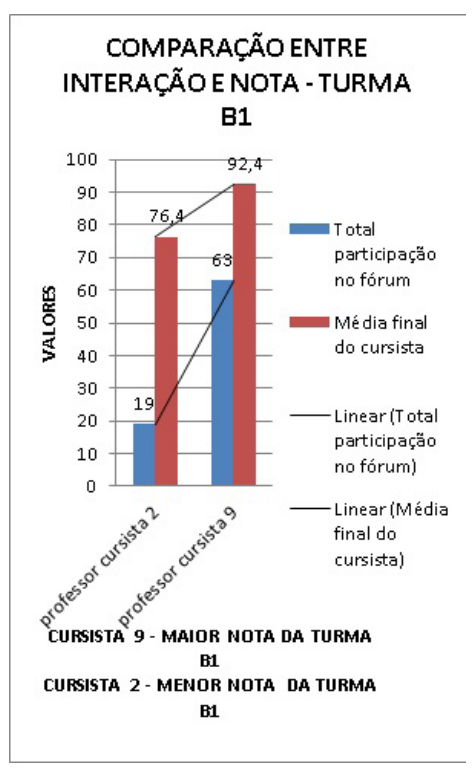

GRÁFICO 1 - Cursistas que obtiveram a maior e a menor média de notas - Turma B1. 


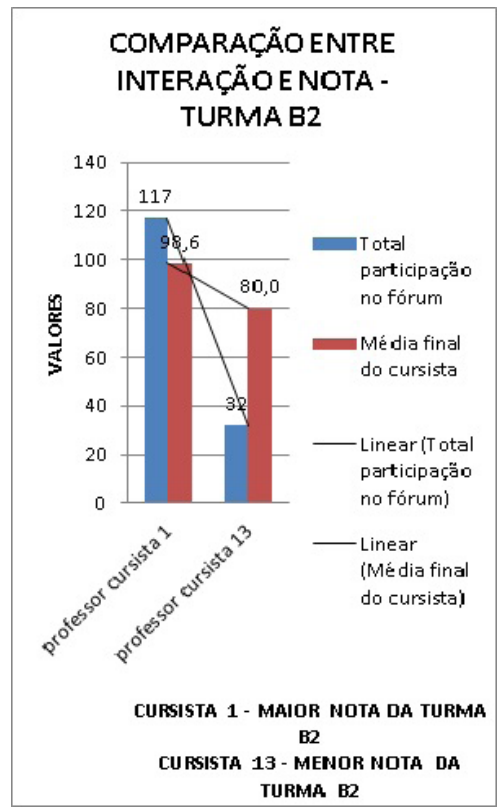

GRÁFICO 2 - Cursistas que obtiveram a maior e a menor média de notas - Turma B2.

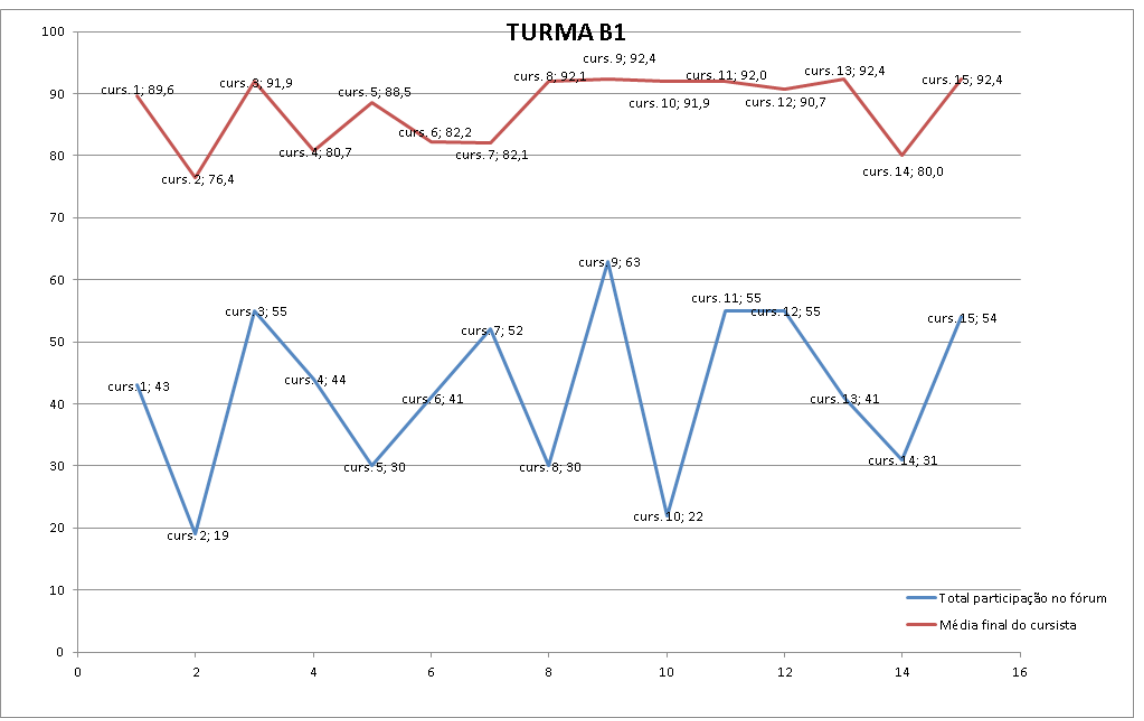

GRÁFICO 3 - Comparando interação e nota dos cursistas da Turma B1. 
No Gráfico 3, percebe-se uma oscilação na turma maior da variável referente à participação no fórum, porém o início e o final das duas linhas das variáveis são coerentes e diretamente proporcionais, pois, se uma aumenta, a outra também o faz. Isso comprova que o quantitativo de interação no fórum interfere diretamente na nota atribuída aos cursistas, com exceção de dois pontos que se referem aos professores cursistas 8 e 10, sendo que esses dois tiveram menos interação, se comparados com os demais, e a nota mais elevada. Nesse caso, deve-se realizar um estudo mais aprofundado para se entender esse fenômeno com o intuito de investigar as características individuais desses dois cursistas, que pode envolver autonomia, autoestudo, etc., bem como a qualidade de interação realizada no processo de ensino/aprendizagem, entre outros fatores.

Em relação à turma $\mathrm{B} 2$, percebe-se que, mesmo com a oscilação da interação, houve uma homogeneidade na variável das notas. Os professores mediadores atribuíam notas de acordo com os seguintes critérios: atendimento à proposta da atividade, coerência e coesão, uso da norma culta, embasamento teórico relacionando as leituras obrigatórias dos módulos.

Isso acontece porque, no processo de ensino e aprendizagem, a mediação se faz mais ou menos necessária, dependendo do momento e do nível em que se encontra o cursista. Isso se explica pela ZDP, que, conforme define Vigotski (2010, p. 97),

é a distância entre o nível de desenvolvimento real, que se costuma determinar através da solução independente de problemas, e o nível de desenvolvimento potencial, determinado através da solução de problemas sob a orientação de um adulto ou em colaboração com companheiros mais capazes.

Sob essa óptica, a mediação acontece justamente para que se chegue ao nível de desenvolvimento potencial e para que haja aquisição de conhecimento, proporcionando a resolução das atividades propostas. Nesse contexto, a interação pode se revelar um aspecto primordial, pois cada pessoa, na sua especificidade, necessita de mais ou menos interação, além de outros fatores que envolvem essa relação, como a linguagem utilizada, a efetividade, a frequência e os canais de comunicação (SALDANHA; CRUZ, 2012). 


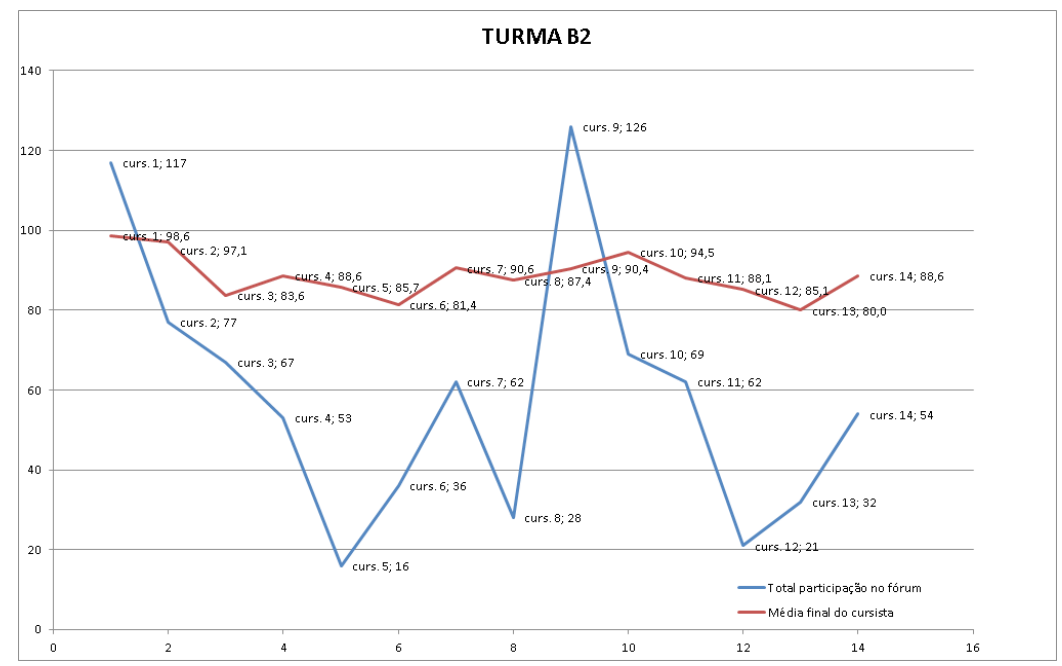

GRÁFICO 4 - Comparando interação e nota dos cursistas da Turma B2.

O Gráfico 4 mostra que houve uma oscilação maior na linha que se refere à interação, se comparado com o gráfico da turma B1. Destaca-se que não houve relação direta entre as duas variáveis (notas e interação), pois apresenta cursistas com pouca interação e notas altas e cursistas com muita interação e notas mais baixas. Mesmo as turmas sendo trabalhadas num mesmo período, num mesmo contexto houve discrepâncias entre as modificáveis. Cabe aqui um estudo mais aprofundado para verificar que aspectos interferiram para que houvesse oscilação entre as variáveis da turma B2. Relacionando os dados obtidos aos objetivos deste estudo, entende-se que, ao analisar o ponto de vista dos professores cursistas quanto ao desenvolvimento de atividades que envolvem a produção coletiva e colaborativa, propostas no fórum do ambiente Moodle, a maioria considerou importante a interação entre os colegas, mesmo afirmando que as contribuições nem sempre foram positivas.

Isso se deve ao fator motivação, pois mesmo tendo um estímulo negativo sobre sua produção, aconteceu uma reação que o estimulou a comprovar sua teoria. Dessa maneira, buscou argumentação nos teóricos estudados e enfatizou seu posto de vista. Nessa situação ocorreu que ambos os sujeitos envolvidos acabaram ampliando sua visão sobre o assunto discutido, pois, pela divergência, alargaramse os diferentes pontos de vista, bem como os argumentos sobre o assunto. 
Dessa forma, a dinâmica que aconteceu no processo de interação entre os professores cursistas no curso de formação continuada proporcionou a construção do conhecimento de forma não linear e irregular, pois os participantes lançaram os argumentos em forma de respostas, posteriormente se lançaram as réplicas e tréplicas e assim se caracterizou o processo dialético.

Já em relação aos dados da entrevista (Quadro 1), que remetem à concepção e à importância dada pelos professores mediadores a respeito do fórum e das interações realizadas entre os cursistas no contexto de um curso de formação continuada de professores, por meio do AVEA, verificou-se que os professores mediadores destacaram a discussão, a argumentação, a sugestão, os feedbacks, as contribuições, visando a auxílio, ajuda, cooperação e a agregação de novos conhecimentos. Todos esses elementos remetem à diversidade existente nos grupos de estudo, pois cada um, em determinado tempo ou ocasião, estabeleceu uma relação de interação com seus pares e/ou com o seu mediador mediante sua necessidade. Essa diversidade é que enriqueceu as contribuições e favoreceu o aprendizado no grupo.

Caso se percebesse um professor cursista que apresentasse mais dificuldades e fosse mais lento na realização das atividades e se o grupo o isolasse, deixaria de acontecer, segundo Vigotski (2010, p. 164) "a transformação de um processo interpessoal (social), num processo intrapessoal, os estágios de internalização; o papel dos aprendizes mais experientes". Isso dificultaria muito o desenvolvimento do potencial dos estudantes que possuem níveis diferentes.

Em relação a verificar se a interação entre os professores cursistas, no fórum, propicia a produção coletiva e colaborativa, percebeu-se que os comentários da questão 10 do questionário aplicado aos cursistas e as respostas de cursistas nas demais questões confirmaram o estímulo dado pela interação para a produção coletiva. Compreende-se que esse processo foi facilitado e motivado, pois quanto mais pessoas envolvidas na participação efetiva de uma ação de construção, menos sobrecarga individual ocorre, em decorrência da distribuição de responsabilidades. Assim, todos foram corresponsáveis pela produção e pelas múltiplas contribuições, o que acabou se tornando rico em pontos de vista, argumentos, ideias, embasamentos teóricos que teceram a produção coletiva. 


\section{Conclusão}

De uma forma geral, constatou-se que a interação social proporcionada na formação contribuiu para o desempenho dos cursistas, bem como para as produções coletivas e colaborativas. Aspecto corroborado pelos dados obtidos por meio do questionário, das entrevistas e da observação direta no Moodle, a fim de verificar as interações realizadas no fórum e as notas atribuídas pelos mediadores.

Entretanto é de suma importância destacar os dados visualizados nos gráficos que comparam as variáveis: notas e quantidade de interação, pois há grande oscilação da variável interação, enquanto a nota permanece constante. Usando uma metáfora: é como se o cursista tivesse que se "alimentar" mais ou menos da interação social, dependendo da necessidade, para manter a sua nota. Porém os gráficos quantitativos não dão respostas qualitativas, cabendo, assim, um estudo mais aprofundado relacionando notas ou conceitos atribuídos aos cursistas com as interações realizadas no AVEA. Conclui-se, então, que a nota ou desempenho do cursista nem sempre tem uma relação diretamente proporcional às interações realizadas. Houve dificuldade em trabalhar com os dados, muito inconstantes, não sendo estes suficientes para se fazer essa afirmativa. Cabem, então, alguns questionamentos: quais são os fatores que interferem na oscilação/variação das interações sociais realizadas no AVEA, uma vez que há grande oscilação durante o curso? Em quais momentos de formação os cursistas mais interagem com o mediador/tutor? Na produção coletiva, na atividade individual?

Em suma, a pesquisa esclareceu alguns dados sobre a problemática levantada, como também levantou outras situações que podem ser exploradas e investigadas com mais profundidade. Dentre elas pode-se citar a motivação e afirmação incisivas dos cursistas em relação à contribuição da interação social na produção colaborativa e coletiva, bem como as reclamações quando o mediador não fornece os feedbacks ou quando a comunicação entre cursista e mediador não alcança o objetivo esperado, além de outros fatores que envolvem essa relação, como a linguagem utilizada, a efetividade, a frequência e os canais de comunicação.

Destaca-se, dessa forma, a valorização e a importância da interação social nos fóruns dos cursos de formação continuada de professores, visto que todos os envolvidos e os próprios registros feitos nos ambientes enfatizam e concretizam essa relação, a fim de alcançarem o seu objetivo na formação e, consequentemente, obterem um bom desempenho no curso. 


\begin{abstract}
Much has been done by answering the need for continuing education of teachers to enhance teaching practice, by the pedagogical mediation through the use of Web 2.0 features, but still little is known about the weight that the interaction that occurs in virtual environments used in these courses has on student ratings. The main objective of this research was to investigate how the amount of social interaction in the virtual forum of a distance course for teachers who work in technology management in schools contributed to their performance and their evaluation. The research investigated the case of the Course "Virtual Learning Environment in the context of Learning and Assessment", offered between 2011 and 2013 by the Municipal Education Coordinators Teaching Support Technology Municipal Education Network Campo Grande, Mato Grosso do Sul and had the participation of two teachers mediators and twenty-nine participant teachers. It was found that the interaction positively permeates the whole process of learning environment, contributing to the performance of the course participants and the collective and collaborative production. However, the links between amount of interaction and positive evaluation are inconclusive, because, in one of the investigated classes, this relationship was direct, but not in the other, suggesting the need for more studies on this issue.
\end{abstract}

Keywords: Interaction. Virtual environment. Evaluation.

\title{
Referências
}

AZANHA, José Mário Pires. Uma idéia de pesquisa educacional. São Paulo. Tese (Livre-docência) - Faculdade de Educação da Universidade de São Paulo, São Paulo, 1990.

BARDIN, Laurence. Análise de Conteúdo. Tradução de Luís Antero Reto e Augusto Pinheiro. São Paulo: Martins Fontes, 1977.

BRASIL. Ministério da Educação. Portaria n. 4.059, de 10 de dezembro de 2004. Disponível em: <http://portal.mec.gov.br/sesu/arquivos/pdf/port4059-2004.pdf>. Acesso em: 12 nov. 2013.

DOUGIAMAS, Martin; TAYLOR, Peter C. Interpretive analysis of an internet-based course constructed using a new courseware tool called Moodle. 2002. Disponível em: <http://dougiamas.com/writing/herdsa 2002/>. Acesso em: 11 set. 2013. 
DOUGIAMAS, Martin; TAYLOR, Peter C. Moodle: Software open-source para a produção de cursos baseados na internet, 2001. Disponível em: <http://moodle. com/>. Acesso em: 11 set. 2013.

FERNANDEZ, Jany Baena. Contribuição da interação no ambiente virtual de ensino e aprendizagem no desempenho de alunos de um curso de formação continuada de professores. Monografia do curso de Especialização em Gestão e Docência em EaD. Universidade Federal de Santa Catarina, Florianópolis, 2013.

GIL, Antônio Carlos. Como elaborar projetos de Pesquisa. 5. ed. São Paulo: Atlas, 2010.

HOFFMANN, Jussara. O jogo do contrário em avaliação. Porto Alegre: Mediação, 2005. História do MOODLE. Disponível em: <http://docs.moodle.org/ all/pt_br/Hist\% C3\%B3ria_do_Moodle>. Acesso em 14 ago. 2013.

KENSKI, Vani Moreira. Novos Processos de interação e comunicação no ensino mediado pelas tecnologias. Cadernos Pedagogia Universitária, USP. Adaptado do capítulo 8 do livro "Tecnologias e ensino presencial e ensino a distância", de Vani Moreira Kenski. São Paulo: Universidade de São Paulo - USP, Pró-Reitoria de Graduação, 2008.

KENSKI, Vani Moreira. Processos de interação e comunicação mediados pelas tecnologias. In: ROSA, Dalva E. G.; SOUZA, Vanilton C. (Org.). Didática e práticas de ensino: interfaces com diferentes saberes e lugares formativos. Rio de Janeiro: DP\&A, 2002.

KENSKI, Vani Moreira. Tecnologias e tempo docente. Campinas, SP: Papirus, 2013.

MOODLE (Sobre o). Disponível em: <http://docs.moodle.org/26/en/About Moodle>. Acesso em: 14 ago. 2013.

NÓVOA, António (Org.). Os professores e a sua formação. Lisboa: Dom Quixote, 1992.

RABELLO, Elaine T.; PASSOS, José Silveira. Vygotsky e o desenvolvimento humano. Disponível em: <http://www.slideshare.net/caiogrimberg/vygotsky-e-odesenvolvimento-humano $>$. Acesso em: 5 ago. 2013.

RONCARELLI, Dóris et al. EaD: uma ferramenta para escolha de Ambiente Virtual de Ensino-Aprendizagem, 2007. Disponível em: <http://www.abed.org.br/ congresso2007/ tc/420200743710PM.pdf>. Acesso em: 20 set. 2013. 
SALDANHA, Camila Teixeira; CRUZ, Dulce Marcia. Estratégias linguísticas interacionais em Fóruns de discussão na EaD: Uma análise linguística. In: CONGRESSO DE CIÊNCIAS DA COMUNICAÇÃO NA REGIÃO SUL Intercom Sul, 13., 2012, Chapecó. Esportes na idade mídia: diversão, informação e educação. Chapecó: Uno Chapecó, 2012. p. 1-14, v. 1.

TOSTES, Simone Correia. Estratégias mediadoras no ambiente virtual. Revista brasileira de Linguística Aplicada (online), Belo Horizonte, v. 11, n. 1, p. 177-197, 2011. ISSN 1984-6398. Disponível em: <http://www.scielo.br/scielo. php?pid=S1984-63982011000100010\&script=sci_abstract\&tlng $=$ pt $>$. Acesso em: 10 maio 2013.

VIGOTSKI, Lev Semenovich. A formação social da mente: o desenvolvimento dos processos psicológicos superiores. Org. de Michel Cole et al.; tradução de José Cipolla Neto, Luís Silveira Menna Barreto e Solange Castro Afeche. 7. ed. São Paulo: Martins Fontes, 2010.

WIKIPÉDIA. Moodle. Disponível em: <http://pt.wikipedia.org/wiki/Moodle> Acesso em: 8 out. 2010.

Submetido em: 13 de maio de 2015. Aceito para publicação em: 08 de outubro de 2015. 